\title{
PENGARUH SUPERVISI KEPALA RUANG MODEL REFLEKTIF TERHADAP KEPUASAN KERJA PERAWAT DI RSUD TUGUREJO PROVINSI JAWA TENGAH
}

\author{
Fatikhah $^{1}$ Nur Zuhri ${ }^{2}$ \\ ${ }^{1,2}$ STIKES Muhammadiyah Kendal \\ Email : nurzuhri750@gmail.com
}

\begin{abstract}
ABSTRAK
Mutu pelayanan keperawatan dipengaruhi oleh kepuasan kerja perawat. Kepuasan kerja perawat yang tidak dikelola dengan baik dapat mengganggu upaya pencapaian tujuan rumah sakit dalam pemberian pelayanan kesehatan yang paripurna dan bermutu. Kepuasan kerja perawat dapat dicapai melalui hubungan yang baik dengan pimpinan. Hubungan yang baik, sejajar, bersifat dukungan dan kolaboratif terdapat dalam supervisi model reflektif. Penelitian ini bertujuan untuk menganalisa pengaruh supervisi kepala ruang model reflektif terhadap kepuasan kerja perawat di RSUD Tugurejo Provinsi Jawa Tengah. Desain penelitian ini adalah quasi-experiment dengan rancangan pre-post-test with control group design. Jumlah sampel yang digunakan adalah 68 responden perawat yang diambil dengan teknik purposive sampling dan terbagi dalam kelompok intervensi $(n=34)$ dan kelompok kontrol $(\mathrm{n}=34)$. Pengumpulan data dilakukan menggunakan kuesioner dan selanjutnya dianalisa dengan uji paired t-test. Hasil uji paired t-test mendapatkan nilai $\mathrm{p}$ sebesar $<0,001$ yang artinya terdapat pengaruh supervisi kepala ruang model reflektif terhadap kepuasan kerja perawat. Supervisi model reflektif dapat digunakan sebagai upaya meningkatkan kepuasan kerja perawat. Kepala ruang sebagai low manajer dapat memerankan fungsi manajemen dengan baik melalui supervisi model reflektif untuk meningkatkan kepuasan kerja perawat.
\end{abstract}

Kata kunci: Kepuasan kerja, perawat, supervisi model reflektif 


\begin{abstract}
The improperly managed job satisfaction of nurses can disrupt the function of the hospital in providing comprehensive and quality health services. The nurses' job satisfaction can be achieved through a good relationship between nurses and hospital leaders. A good and equal as well as supporting and collaborative relationshipis reflected in the supervision of reflective model. This study aimed to analyze the influence of head nurses' supervision of reflective model on the job satisfaction of nursesat Tugurejo Regional Public Hospital in Central Java Province. This study employed a pre-post-test quasi-experimental design with a control group. The samples were 68 nurses recruited by purposive sampling and were assigned to the intervention group $(n=34)$ and control group $(n=34)$. The data were collected using questionnaires and then analyzed using the paired t-test. The result of paired $t$-test test obtained a p-value of $<0.001$, indicating that there were influences of the head nurses' supervision of reflective model on the nurses' job satisfaction. The reflectivemodel supervision can be used as an alternative to improve the job satisfaction among the nurses. The head nurses as a low-level manager can perform the management functions well through the reflective model supervision to improve the nurses' job satisfaction.
\end{abstract}

Keywords: Job satisfaction, nurses, reflective model supervision

\section{PENDAHULUAN}

Pelayanan keperawatan memegang peranan penting dalam mewujudkan pelayanan kesehatan yang bermutu dan paripurna di rumah sakit. Rumah sakit dalam mewujudkan pelayanan yang paripurna memerlukan sumber daya manusia profesional (Ilyas Y., 2004), salah satunya adalah sumber daya keperawatan. Sumber daya keperawatan sebagai sumber daya profesional dan berjumlah paling besar di pelayanan kesehatan menjadi alasan tersebut.

Kemenkes RI menyebutkan bahwa jumlah perawat di Indonesia mencapai 237.181 perawat. Perawat di Indonesia jumlahnya paling banyak bila dibandingkan dengan tenaga kesehatan lainnya, yaitu 50-60\% di rumah sakit dan memiliki jam kerja 24 jam melalui penugasan shift sehingga perannya berkontribusi besar dalam meningkatkan mutu pelayanan kesehatan. Studi pendahuluan yang dilakukan peneliti di RSUD Tugurejo Provinsi Jawa Tengah,pada saat ini memiliki karyawan dengan jumlah keseluruhan 1161 karyawan, dimana terdapat 413 (Wijono D, 2000). Data tersebut menunjukkandari segi jumlah dan peran sangat berkontribusi dalam menentukan mutu pelayanan kesehatan di rumah sakit.Rumah sakit harus dapat mengelola tenaga keperawatan guna meningkatkan mutu pelayanan kesehatan.

Kepuasan kerja perawat menurut Manojlovich M, Spence Laschinger HK secara umum dapat diartikan sebagai suatu sikap puas seseorang terhadap pekerjaannya. Kepuasan kerja merupakan fungsi dari unsur- unsur di tempat kerja 
termasuk sikap dan perilaku (Mangkunegara AAAP, 2000). Stephen P. Robbins menyatakan bahwa kepuasan kerja merupakan suatu sikap umum seorang individu terhadap pekerjaannya. Kepuasan kerja dapat meningkatkan produktifitas walaupun tidak dapat dilihat secara langsung pada saat itu juga. Kepuasan kerja perawat adalah suatu sikap individu perawat terhadap pekerjaannya dan fungsi unsur-unsur ditempat kerja, serta dapat meningkatkan produktifitas walaupun tidak dapat dilihat secara langsung pada saat itu juga (Baumann A., 2007).

Kepuasan kerja perawat masih menunjukkan adanya fenomena yang signifikan pada beberapa penelitian, diantaranya Pietersen, C. dalam penelitian menemukan $63 \%$ tidak puas dengan supervisi. Penelitian Selebi,C. dan Minnaar, A. menunjukkan bahwa kepuasan kerja perawat yang masih sangat rendah mencapai $35 \%$ dan yang kategori rendah sebanyak 42\%. Penelitian dari Noras JU. dan Sartika RAD, menyatakan $77,5 \%$ perawat merasa tidak puas dalam bekerja sebagai perawat pelaksana. Baumann A. mengemukakan bahwa di Amerika Serikat, Kanada, Inggris dan Jerman menunjukkan $41 \%$ perawat mengalami ketidakpuasan dalam bekerja (Supratman, Sudaryanto A., 2008).

Studi pendahuluan di RSUD Tugurejo Provinsi Jawa Tengah didapatkan bahwa saat ini belum mengukur kepuasan kerja secara khusus pada perawat. Survei kepuasan kerja perawat pernah dilakukan hanya pada saat penelitian Wuryanto E. dimana hanya mengidentifikasi bahwa karakteristik individu dan lingkungan kerja berpengaruh terhadap kepuasan kerja
perawat.Studi pendahuluan terhadap 30 perawat di RSUD Tugurejo Provinsi Jawa Tengah tentang kepuasan kerja perawat didapatkan hasil sebanyak 13 perawat $(43,3 \%)$ menyatakan puas terhadap pekerjaan dan 17 perawat $(56,7 \%)$ menyatakan tidak puas dengan pekerjaannya. Angka ketidakpuasan perawat ini dapat dijadikan sebagai suatu indikator jika kondisi ini diabaikan maka diwaktu yang akan datang akan berdampak terhadap tujuan dari organisasi dalam hal ini rumah sakit (RSUD Tugurejo Provinsi Jawa tengah, 2016).

Kepuasan kerja perawat yang tidak dikelola dengan baik dapat menimbulkan gejala-gejala sebagai dampaknya. Hasil studi pendahuluan di Bagian Organisasi dan Kepegawaian RSUD Tugurejo Propinsi Jawa Tengah menunjukkan adanya angka turn over perawat dari tahun 2015 dan 2016 sebanyak 11 perawat mengundurkan diri dan sebanyak 8 perawat mengajukan mutasi. Kasi Keperawatan Rawat Inap menyatakan tiap bulan rerata 12 perawat bermasalah pada absensinya. Ketua Komite Keperawatan dalam wawancara menyatakan hasil kinerja perawat dari segi asuhan keperawatan pada bulan november 2016 masih dalam kategori baik tetapi masih perlu ditingkatkan lagi. Gejala dampak tersebut harus segera dikelola melalui upaya-upaya agar tidak mengganggu kondisi didalam suatu organisasi atau rumah sakit (RSUD Tugurejo Provinsi Jawa tengah, 2016).

Kepuasan kerja perawat dapat diidentifikasi dengan pendekatan teori Dua Faktor dari Hezberg, yang menyatakan bahwa faktor-faktor yang mempengaruhi kepuasan yaitu faktor intrinsik pekerjaan 
dan ekstrinsik pekerjaan. Faktor intrinsik (job content) berkaitan dengan isi pekerjaan yang meliputi prestasi, pengakuan, pekerjaan itu sendiri, tanggung jawab, kemajuan, pertumbuhan dan perkembangan pribadi. Faktor ekstrinsik berkaitan dengan kedaan pekerjaan (job context) yang meliputi gaji, jaminan pekerjaan, kondisi kerja, status, kebijakan, kualitas hubungan antarpribadi dengan atasan, bawahan, dan sesama karyawan, serta kualitas supervisi (Siagian SP., 2011).

Penelitian yang pernah dilakukan sebelumnya menjelaskan bahwa terciptanya kepuasan kerja pada perawat ini dapat dipengaruhi oleh beberapa faktor yang menjadi penyebab, diantaranyafaktor burnout, rotasi dan stres kerja, iklim kerja, administrasi, rendahnya konflik, dukungan kepemimpinan, faktor manajemen organisasi, faktor gaji, lingkungan kerja, usia, lama kerja, dan karakteristik pribadi pemimpin, serta kompetensi manajerial pemimpin. Jayasuria R. et al, dan Mayasari A. dalam penelitiannya juga mengemukakan bahwa faktor supervisi berpengaruh terhadap kepuasan kerja perawat. Penelitian di Amerika menunjukkan bahwa dari 72 perawat yang diteliti mengatakan bahwa faktor yang paling berpengaruh terhadap kepuasan kerja adalah dukungan supervisi, dimana supervisi merupakan kegiatan dalam fungsi-fungsi manajemen. Cortese CC. dan Dogan $H$. juga mengemukakan bahwa faktor supervisi merupakan aspek penting yang mempengaruhi kepuasan kerja perawat (Hasibuan M., 2001).

Studi pendahuluan di RSUD Tugurejo Provinsi Jawa Tengah pada 17 perawat yang menyatakan tidak puas, didapatkan data bahwa penyebab ketidakpuasan tersebut disebabkan sistem rotasi sebanyak 4 perawat $(23,52 \%)$, disebabkan promosi karir sebanyak 2 perawat $(11,76 \%)$, stres karena situasi kerja sebanyak 3 perawat $(17,64 \%)$, dan tidak puas dengan cara bimbingan dan pengarahan dari kepala ruang sebanyak 8 perawat $(47,06 \%)$. Zhang L, You L, et al juga mengemukakan bahwa supervisi merupakan faktor penting yang dapat mempengaruhi kepuasan kerja perawat, maka upaya yang harus dioptimalkan adalah dengan memperbaiki lingkungan kerja yang baik, dan diperkuat oleh Negussie N, Demissie A. bahwa meningkatkan kepuasan kerja perawat dengan menerapkan gaya kepemimpinan transformasional dan melalui supervisi.

Supervisi termasuk dalam actuating dalam fungsi manajemen. Fungsi manajemen secara umum terdiri dari planing, organizing, actuating dan controling. Supratman dan Sudaryanto A. menyatakan bahwa fakta menunjukkan pelaksanaan supervisi keperawatan di berbagai rumah sakit belum optimal dan perawat pada sebagian besar rumah sakit di Indonesia tidak mampu memerankan fungsi manajemen dengan baik. Penelitian Mularso menemukan bahwa kegiatan supervisi lebih banyak pada kegiatan "pengawasan" bukan pada kegiatan bimbingan, observasi dan menilai. Supervisi yang diterapkan dengan tepat akan menyebabkan perasaan puas pada perawat dikarenakan merasa diterima, dihargai, dan dilibatkan sehingga akan muncul komitmen pada organisasi untuk senantiasa meningkatkan pelayanan keperawatan (Wibowo, 2008).

Studi pendahuluan di RSUD Tugurejo Propinsi Jawa Tengah terhadap 3 kepala 
ruang sebagai supervisor ruangan bahwa dalam melakukan supervisi dilakukan dengan situasional, cenderung bersifat pengawasan, minim kegiatan yang bersifat bimbingan, pengarahan, dan memberikan umpan balik dengan baik. Pihak manajerial sudah mengupayakan perbaikan, baik dalam bentuk pelatihan ataupun arahan pada saat rapat rutin bidang keperawatan, tetapi pada pelaksanaanya belum sesuai dengan fungsi supervisi sebagaimana mestinya. Model supervisi diantaranya adalah model psikoanalitik, model psycodinamik sistem, model kadushin, model proctor, model peplau dan model reflektif. Dari beberapa model tersebut, supervisi model reflektif dapat memaksimalkan kekuatan dalam lingkungan kerja melalui konsep hubungan yang sejajar dan bersifat dukungan dan kolaboratif antara supervisor dengan perawat (Dharma A., 2004).

Supervisi model reflektif dilakukan dengan cara mengarahkan dengan ilmiah dari peristiwa, situasi, kondisi dan tindakan yang terjadi di klinis. Supervisi reflektif bertujuan agar perawat dapat memberikan suatu input untuk meningkatkan pelayanan keperawatan kearah yang lebih baik. Beberapa penelitian menyatakan supervisi model reflektif ini dapat mempengaruhi perilaku keselamatan pasien, mampu mempengaruhi tingkat stres perawat dengan berbagi pengalaman klinis dan mendorong untuk mengembangkan kemampuan dan perbaikan lebih lanjut pada staf, dan mampu mempengaruhi kesehatan mental tenaga kesehatan. Melalui supervisi yang bersifat reflektif, diharapkan kepala ruang sebagai low manajer dapat melaksanakan supervisi sebagai salah satu fungsi dalam manajemen agar dapat meningkatkan kepuasan kerja perawat.

\section{METODE PENELITIAN}

A. Jenis dan Rancangan Penelitian

Jenis penelitian yang digunakan dalam penelitian ini adalah Quasi Experiment (eksperimen semu) dengan rancangan pre-post-test with control group design yaitu terdapat dua kelompok yang dipilih sebagai objek penelitian. Kelompok pertama mendapat intervensi dan kelompok kedua tidak mendapat intervensi. Kelompok kedua ini digunakan sebagai kelompok pembanding. Penelitian ini dilakukan untuk melihat pengaruh supervisi reflektif terhadap kepuasan kerja perawat dengan membandingkan kelompok intervensi yang melaksanakan supervisi model reflektif dan kontrol yang tidak melakukan supervisi model reflektif. Pengukuran akhir dilakukan setelah dilaksanakan supervisi model reflektif.

B. Populasi dan Sampel Penelitian

1. Populasi

Populasi adalah wilayah generalisasi yang terdiri atas obyek atau subyek yang mempunyai kualitas dan karakteristik tertentu yang ditetapkan oleh peneliti untuk dipelajari dan kemudian ditarik kesimpulannya. ${ }^{76}$ Adapun populasi yang akan diteliti adalah seluruh perawat di RSUD Tugurejo Provinsi Jawa Tengah yang berjumlah 413 orang.

\section{Sampel}

Sampel adalah bagian dari jumlah dan karakteristik yang dimiliki oleh populasi. Sampel 
dalam penelitian diambil dari sebagian populasi yaitu perawat di
RSUD Tugurejo Provinsi Jawa Tengah.

Rumus besar sampel sebagai berikut :

$$
\mathrm{n}=\frac{z_{\mathrm{l}-\alpha / 2}^{2}\left(2 \sigma^{2}\right)}{\mathrm{d}^{2}}
$$

Keterangan :

$\mathrm{n} 1=\mathrm{n} 2=$ besar sampel minimum

$\mathrm{Z}_{1-\alpha / 2}=$ nilai distribusi normal baku (tabel $\left.\mathrm{Z}\right)$ pada $\alpha$ tertentu $(1,96)$

$\sigma^{2}=$ harga varians di populasi $100 \%(0,100)$

$\mathrm{d}=$ kesalahan (absolut) yang dapat ditolerir 5\% $(0,05)$

$$
\begin{gathered}
\mathrm{n}=\frac{3,8416 \cdot(2 \cdot 0,01)}{0,0025} \\
\mathrm{n}=\frac{3,8416 \cdot(0,02)}{0,0025} \\
\mathrm{n}=\frac{0,076832}{0,0025}
\end{gathered}
$$$$
\mathrm{n} 1=\mathrm{n} 2=30,7 \text { di bulatkan menjadi } 31
$$

Berdasarkan penghitungan rumus, maka sampel yang dibutuhkan adalah 31 responden, namun akan ditambahkan $10 \%$ untuk partisipasi adanya droup out sehingga $31+3=34$ responden. Jadi responden untuk kelompok intervensi dan kontrol adalah 34 responden, sehingga total sampel yang dibutuhkan adalah 68 responden.

Teknik sampling yang digunakan dalam penelitian ini adalah purposive sampling yaitu penentuan sampel berdasarkan kriteria yang ditetapkan oleh peneliti. Populasi memiliki kesempatan yang sama untuk dilakukan penelitian yang memenuhi 
kriteria inklusi dijadikan

\section{HASIL DAN PEMBAHASAN}

1. HASIL

Hasil penelitian yang telah dilaksanakan pada tanggal 12 Mei 2017 sampai dengan 3 Juli 2017 di RSUD Tugurejo Provinsi Jawa Tengah di Semarang dan RSUD Dr. Moewardi Provinsi Jawa Tengah di Surakarta. Penelitian menggunakan 3 (tiga) ruang kelompok intervensi dan 2 (dua) ruang kelompok kontrol, dengan perincian ruangan yang dijadikan kelompok intervensi yaitu Kenanga ( Kelas 1), Nusa Indah (VIP), dan Dahlia 1 (Kelas 3), sedangkan ruang yang dijadikan kelompok kontrol yaitu Mawar 2 dan Melati 3. Terdapat 5 kepala ruang dan 68 perawat yang dilibatkan dalam pelatihan dengan perincian 3 kepala ruang dan 34 perawat sebagai kelompok intervensi serta2 kepala ruang dan 34 perawat sebagai kelompok kontrol.

\section{a. Karakteristik Responden}

Karakteristik responden pada penelitian ini meliputi umur, jenis kelamin, status pernikahan, tingkat pendidikan dan masa kerja. Karakteristik responden ini diolah secara statistik yang disajikan sesuai jenis data yang diperoleh, yaitu data kategori terdiri usia, jenis kelamin, tingkat pendidikan, status pernikahan dan masa kerja.

Jenis kelamin pada kelompok intervensi perempuan sebanyak 22 orang $(64,7 \%)$ dan laki-laki sebagai sampel penelitian

sebanyak 12 orang $(35,3 \%)$ sementara responden kelompok kontrol perempuan sebanyak 21 orang $(61,8 \%)$ dan laki-laki sebanyak 13 orang $(38,2 \%)$, hasil uji kesetaraan adalah 0,801 dengan makna tidak ada beda. Tingkat pendidikan responden kelompok intervensi sama besar antara S1 dan DIII Keperawatan, masing-masing 17 orang $(50,0 \%)$, sementara responden kelompok kontrol sebagian besar adalah D III Keperawatan yaitu 22 orang $(64,7 \%)$ dan S1 Keperawatan 12 orang $(35,3 \%)$ dengan nilai $p$ value 0,220 . Status perkawinan pada kelompok intervensi sebagian besar responden dalam kategori kawin yaitu sebanyak 26 orang $(76,5 \%)$ dan yang belum kawin sebanyak 8 orang $(23,5 \%)$, responden kelompok kontrol yaitu kawin sebanyak 27 orang $(79,4 \%)$ dan yang belum kawin sebanyak 7 orang $(20,6 \%)$ sementara nilai $\mathrm{p}$ value adalah 0,770 dengan makna tidak ada beda.

Nilai mean kepuasan kerja sebelum dilakukan intervensi pada kelompok intervensi adalah 82,65 dan pada kelompok kontrol adalah 113,03. Analisis menggunakan uji tidak berpasangan, hasil uji normalitas tidak berdistribusi normal, sehingga analisis data menggunakan Man Whitney. Hasil analisis didapatkan nilai $\mathrm{p}$ sebesar < 0,001; artinya bahwa terdapat perbedaan kepuasan kerja perawat sebelum intervensi 
antara kelompok eksperimen dengan kelompok kontrol.

Nilai mean kepuasan kerja responden setelah intervensi pada kelompok intervensi adalah 158,67 dan pada kelompok kontrol adalah 114,79. Hasil uji Man Whitney didapatkan nilai $\mathrm{p}$ sebesar < 0,001; artinya bahwa terdapat perbedaan kepuasan kerja perawat setelah intervensi antara kelompok intervensi dengan kelompok kontrol. Hasil nilai mean kelompok intervensi lebih tinggi dibandingkan dengan kelompok kontrol, artinya kepuasan kerja pada kelompok intervensi menunjukkan ada peningkatan bermakna.

Setelah dilakukan uji kenormalan pada kelompok intervensi ditemukan data berdistribusi normal sehingga analisis data yang digunakan adalah Paired Sample $t$ Test. Hasil analisis didapatkan nilai mean kepuasan kerja perawat pada kelompok intervensi sebelum dilakukan intervensi adalah 82,65 dan setelah intervensi adalah 158,67. Hasil Paired Sampel $t$ Test didapatkan nilai $\mathrm{p}$ sebesar < 0,001; artinya bahwa terbukti setelah intervensi supervisi Model Reflektif berpengaruh terhadap kepuasan kerja perawat pada kelompok intervensi.

Nilai kepuasan kerja sebelum dan sesudah intervensi pada kelompok intervensi selisih nilai mean adalah 76,02 dengan nilai SD 15,30; nilai minimal 36 dan nilai maksimal 91. Pada kelompok kontrol selisih mean adalah 1,76; nilai SD 2,74; nilai minimal 1 dan nilai maksimal 8 . Uji kenormalan ditemukan data berdistribusi tidak normal sehingga analisis data yang digunakan adalah Mann Whitney Test. Hasil uji beda dengan Mann Whitney Test didapatkan nilai $\mathrm{p}$ value sebesar < 0,001; artinya bahwa pada kelompok intervensi dan kelompok kontrol setelah diberikan intervensi terdapat perbedaan yang bermakna. Supervisi model reflektif terbukti mempengaruhi dan meningkatkan kepuasan kerja perawat pada kelompok intervensi.

\section{PEMBAHASAN}

Pembahasan yang meliputi interprestasi hasil dari penelitian dan keterbatasan penelitian yang telah dilakukan. Interpretasi hasil penelitian dilakukan dengan membandingkan hasil penelitian dengan tinjauan pustaka serta hasil-hasil penelitian yang relevan.Penelitian ini bertujuan untuk mengetahui pengaruh supervisi kepala ruang model reflektif terhadap terhadap kepuasan kerja perawat di RSUD Tugurejo Provinsi Jawa Tengah.

\section{a. Gambaran \\ Responden}

Karakteristik

Karakteristik responden dalam penelitian ini terdiri dari umur, masa kerja, jenis kelamin, tingkat pendidikan, dan status perkawinan. Penelitian ini menggunakan uji homogenitas untuk mengetahui kesetaraan responden antara kelompok intervensi dan kelompok kontrol. 
Uji kesetaraan karakteristik umur responden menemukan bahwa nilai mean umur responden pada kelompok intervensi adalah 30,15 dan pada kelompok kontrol adalah 31,20; hasil uji kesetaraan dua kelompok dengan Mann Whitney didapatkan hasil $\mathrm{p}$ value sebesar 0,975 yang artinya tidak terdapat perbedaan karakteristik umur pada homogenitas kedua kelompok. Uji kesetaraan karakteristik masa kerja pada kelompok eksperimen didapatkan nilai mean adalah 5,06 dan kelompok kontrol adalah 5,83; hasil uji beda kedua kelompok didapatkan nilai $\mathrm{p}$ value 0,774 (tidak ada perbedaan). Uji kesetaraan karakteristik jenis kelamin didapatkan hasil uji kesetaraan dengan chi square test didapatkan nilai $\mathrm{p}$ value 0,801 dimana artinya pada kedua kelompok tidak ada perbedaan karakteristik jenis kelamin. Karakteristik tingkat pendidikan responden kedua kelompok dengan uji kesetaraan menggunakan uji chi squre test didapatkan hasil $\mathrm{p}$ value sebesar 0,220 artinya tidak ada perbedaan karakteristik tingkat pendidikan pada kelompok intervensi dan kelompok kontrol. Karakteristik status perkawinan responden pada kelompok intervensi dan kelompok kontrol didapatlan hasil uji kesetaraan $\mathrm{p}$ value sebesar 0,770; artinya tidak terdapat perbedaan pada karakteristik tingkat pendidikan kedua kelompok. Hasil penelitian ini didapatkan kesimpulan tidak terdapat perbedaan pada karakteristik umur, masa kerja, jenis kelamin, tingkat pendidikan, dan status perkawinan antara kelompok intervensi dan kelompok kontrol. Homogenitas karakteristik kedua kelompok agar tidak mempengaruhi kepuasan kerja pada masing- masing kelompok tersebut.

b. Perbedaan Kepuasan Kerja Perawat Pada Kelompok Intervensi dan Kontrol Sebelum dan Setelah Kelompok Intervensi Dilakukan Supervisi Model Reflektif.

Hasil penelitian menunjukkan bahwa kepuasan kerja pada kelompok intervensi sebelum dilakukan supervisi model reflektif didapatkan nilai mean sebesar 82,65; dengan nilai minimal 52 dan nilai tertinggi 135 , serta nilai standar deviasi 20,46. Pada kelompok kontrol sebelum dilakukan intervensi (pada kelompok kontrol) nilai mean 113,03; dengan nilai mean minimal 66 dan maksimal 135, serta nilai standar deviasi sebesar 20,73. Hasil uji tidak berpasangan penelitian dengan menggunakan uji Man Whitney didapatkan nilai p sebesar < 0,001; artinya bahwa terdapat perbedaan kepuasan kerja perawat sebelum intervensi antara kelompok intervensi dengan kelompok kontrol.

c. Pengaruh Supervisi Model Reflektif Terhadap Kepuasan Kerja Perawat Pada Kelompok Intervensi

Penelitian ini menghasilkan data bahwa ada perbedaan yang bermakna antara kepuasan kerja 
perawat setelah dilakukan intervensi berupa supervisi model reflektif pada kelompok intervensi. Hasil uji beda antara kepuasan kerja pada kelompok eksperimen sebelum dan sesudah dilakukan intervensi berupa supervisi model reflektif didapatkan nilai mean sebesar 76,02. Hasil Paired Sampel $t$ Test didapatkan nilai $\mathrm{p}$ sebesar < 0,001; artinya bahwa terdapat perbedaan kepuasan kerja perawat sebelum dan setelah intervensi pada kelompok eksperimen.

\section{SIMPULAN}

Sesuai dengan tujuan penelitian yang telah ditetapkan, maka penelitian ini dapat mengambil simpulan, yaitu sebagai berikut

1. Terdapat perbedaan kepuasan kerja pada kelompok intervensi dan kelompok kontrolpada saat sebelum dan sesudah intervensi supervisi model reflektif.

2. Hasil Paired Sampel $t$ Test didapatkan nilai $\mathrm{p}$ sebesar $<0,001$ artinya hasil penelitian ini menunjukkan bahwa supervisi kepala ruang dengan model reflektif terbukti mempengaruhi kepuasan kerja perawat

\section{UCAPAN TERIMAKASIH}

1. Direktur RSUD Tugurejo Semarang beserta Staf dan Perawat

2. Ketua Stikes Muhammadiyah Kendal beserta Staf dan Karyawan

\section{DAFTAR PUSTAKA}

Ilyas Y. Perencanaan SDM Rumah Sakit Teori, Metoda dan Formula. Depok: Pusat Kajian Ekonomi Kesehatan, Fakultas Kesehatan Masyarakat, 2004.

Kementerian Kesehatan republik Indonesia. Profil Kesehatan Indonesia Tahun 2014. Jakarta: Kementerian Kesehatan Republik Indonesiahttp://www.kemkes.go.id (2015).

RSUD Tugurejo Provinsi Jawa tengah. Data Keperawatan Rumah Sakit Umum daerah Tugurejo Provinsi Jawa Tengah. 2016.

Wijono D. Manajemen Mutu Pelayanan Kesehatan. Cetakan II. Surabaya: Airlangga University Press, 2000.

Handoko TH. Manajemen Personalia dan Sumberdaya Manusia (Edisi 2). edisi 2. Yogyakarta: BPFE Yogyakarta, 2008.

Mangkunegara AAAP. Manajemen sumber daya manusia perusahaan. Bandung: Remaja Rosdakarya, 2000.

Baumann A. Positive Practice Environment: Quality Workplaces = Quality Patient Care, Information and Action Tool Kit. International Council of Nurses, 2007.

Wuryanto E. Hubungan Lingkungan Kerja dan Karakteristik Individu dengan Kepuasan Kerja Perawat di Rumah Sakit Umum Daerah Tugurejo 
Semarang. Universitas Indonesia, 2010 .

Mayasari A. Analisis Pengaruh Persepsi Faktor Manajemen Keperawatan terhadap Tingkat Kepuasan Kerja Perawat di Ruang Rawat Inap RSUD Kota Semarang. Universitas Diponegorohttp://eprints.undip.ac.id/ 16282/ (2009, accessed 3 May 2017.

Deloach R, Monroe J. Job Satisfaction Among Hospice Workers: What Managers Need to Know. Health Care Manag (Frederick) 2004; 23: 209-219.

Cortese CC. Job satisfaction of Italian nurses: an exploratory study. $J$ Nurs Manag 2007; 15: 303-312.

Supratman, Sudaryanto A. Model-Model Supervisi Keperawatan Klinik. Ber Ilmu Keperawatan 2008; 1: 193196.

Mularso. Supervisi keperawatan di RSUD Dr. Abdul Aziz SIngkawang. Universitas GadjahMadahttp://etd.repository.ug m.ac.id/index.php?mod=penelitian_d etail\&sub $=$ Penelitian Detail\&act=view\&typ=html\&buku_i d=34812 (2007, accessed 3 May 2017).

American Nurse Association, National Council of State Boards of Nursing. Joint Statement on Delegation. Am Nurses Assoc. 2005.

Keliat BA. Model Praktik Keperawatan Profesional Jiwa. Jakarta EGC. 2009.
Yulita Y. Pengaruh Supervisi Model Reflekstif Interaktif terhadap Perilaku Keselamatan Perawat pada Bahaya Agen Biologik di RSUD Provinsi Kepulauan Riau Tanjung Uban. Universitas Indonesia, 2013.

Rusmegawati. Pengaruh Supervisi Reflektif Interaktif Terhadap Keterampilan Berfikir Kritis Perawat dalam Melaksanakan Asuhan Keperawatan di IRNA RS. Dr. H. M Ansari Saleh Banjarmasin. Universitas Indonesia, 2011.

Rivai V. Manajemen sumber daya manusia untuk perusahaan: dari teori ke praktik. Jakarta: Raja Grafindo Persada, 2004.

Dariyo A. Psikologi Perkembangan Dewasa Muda. Jakarta: Grasindo, 2003.

Siagian SP. Manajemen sumber daya manusia. Edisi 1, Cetakan 19. Jakarta: Bumi aksara, 2011.

Hasibuan M. Manajemen Sumber Daya Manusia: pengertian dasar, pengertian, dan masalah. Jakarta: Toko Gunung Agung, 2001.

Wibowo. Manajemen Kinerja. jakarta: Rajawali Pers, 2008.

Astuty M. Hubungan Pelaksanaan Fungsi Pengarahan Kepala Ruangan dengan Kepuasan Kerja Perawat Pelaksana di Rumah Sakit Haji Jakarta. Universitas Indonesia, 2011. 
Gillies DA. Nursing management: $a$ systems approach. 3rd edition. Philadelphia: Saunders, 1994.

Nursalam. Manajemen Keperawatan: aplikasi dalam praktik keperawatan profesional. Edisi 3. Jakarta: Salemba Medika, 2011.

Suarly, Bahtiar Y. Manajemen Keperawatan: Dengan Pendekatan Praktis. Jakarta: Erlangga, 2009.

Dharma A. Manajemen Supervisi (petunjuk praktis bagi para supervisor). edisi 6. Jakarta: Raja Grafindo Persada, 2004.

Suyanto. Mengenal kepemimpinan dan manajemen keperawatan di Rumah Sakit. Yogyakarta: Mitra Cendekia Jogjakarta, 2009.

Sugiharto AS. Manajemen Keperawatan: Aplikasi MPKP di rumah sakit. Cetakan 1. Jakarta: EGC, 2012.

Nasir A, Muhith A, Ideputri ME. Buku ajar metodologi penelitian kesehatan. Cetakan 1. Yogyakarta: Nuha Medika, 2011.

Sugiyono. Metode Penelitian Kuantitatif, Kualitatif dan R\&amp;D. Cetakan 13. Bandung: Alfabeta, 2011.

Notoatmodjo S. Metodologi Penelitian Kesehatan. 2010; 243.

Arikunto S. Prosedur Penelitian: suatu pendekatan praktik. Edisi Revi. Jakarta: Rineka Cipta, 2006.
Nursalam., Salemba Medika. Konsep dan penerapan metodologi penelitian ilmu keperawatan : pedoman skripsi, tesis, dan instrumen penelitian keperawatan. Ed. 2. Jakarta: Salemba Medika, 2008.

Asegid A, Belachew T, Yimam E. Factors Influencing Job Satisfaction and Anticipated Turnover among Nurses in Sidama Zone Public Health Facilities, South Ethiopia. Nurs Res Pract; 2014. Epub ahead of print 2014. DOI: $10.1155 / 2014 / 909768$. 